\title{
Sigma Phase Characterization in AISI 316 Stainless Steel
}

\author{
Xiaoli Tang* \\ * Swagelok Company, 29500 Solon Road, Solon, OH 44139, USA
}

Sigma phase $(\sigma)$ is a chromium/molybdenum-rich intermetallic phase found in the Fe-Cr-Mo system, which occurs when the material dwells or slow cools through the temperature range of 550$1050^{\circ} \mathrm{C}$. Thermodynamically, it is possible for this phase to form in standard AISI 316 stainless steel, although in practice it has rarely been seen. With the "lean" chemical composition of AISI 316 stainless steel, (that is its relatively low chromium and molybdenum contents), the kinetics of $\sigma$ phase formation are slow. In addition, in these types of lean stainless steels, the general recognized upper temperature limit for $\sigma$ existence is around $1050^{\circ} \mathrm{C}$. As most austenitic stainless steels are supplied with solution annealing (usually at or above $1050^{\circ} \mathrm{C}$ ) as the final heat treatment to achieve optimum corrosion resistance, it is not surprising that the existence and impact of $\sigma$ phase in AISI 316 stainless steel have been largely overlooked. However, the increased use of the continuous casting method of stainless steel manufacturing is resulting in a wider occurrence of $\sigma$ phase in AISI 316 stainless steel. As compared to static ingot cast stainless steels, continuously cast billets experience more chemical segregation at the center, resulting in localized areas enriched in $\mathrm{Cr}$ and Mo. As the result, $\sigma$ phase is more prone to form and at a much fast kinetics than historically thought. The detrimental effects of $\sigma$ phase on mechanical properties and corrosion resistance are well known. Every measure should be taken to prevent this phase from existing in stainless steels. However, revealing the presence of this phase in AISI 316 stainless steel requires carefully applied metallographic techniques. In this study, some successful characterization methods are discussed.

Material used in this study is standard AISI 316 stainless steel manufactured by electric arc furnace melting with argon-oxygen decarburization (AOD) process and continuously cast into billets. Specimens were taken from a round bar of over $50 \mathrm{~mm}$ in diameter and solution annealed at $1065^{\circ} \mathrm{C}$. The section parallel to the longitudinal direction of the bar was chosen for the characterization because of the good visibility of elongated phases on this section. Although common etchants for stainless steels, such as Kalling's, sufficiently revealed the presence of $\sigma$ phase from the austenitic matrix by outlining the interfaces between austenite matrix and $\sigma$ phase, it also revealed retained ferrite, a common feature of AISI 316 stainless steel, in the same fashion. This made it difficult to separate the two phases, and may have contributed to the lack of recognition of $\sigma$ phase in this material. More effective methods usually involve tint etching. The tint etching method successfully reveals $\sigma$ phase and differentiates it from other phases, such as retained ferrite and MnS inclusions.

A routinely used tint etchant is Groesbeck's solution [1]. Although the recommended etching condition was $60-90^{\circ} \mathrm{C}$ for $1-10$ minutes, in this study it was found that in the temperature range 60 $70^{\circ} \mathrm{C}, 3-4$ minute submerging etching gave very good results for AISI 316 stainless steel. After such etching, $\sigma$ phase exhibited an orange-brown color, while the retained ferrite showed a light brown color and $\mathrm{MnS}$ the dark gray feature. Too high a temperature or too long a time could cause over etching, which would either darken the $\sigma$ phase too much and make it difficult to be differentiated from $\mathrm{MnS}$, or stain the ferrite dark brown and made it similar to the $\sigma$ phase. The appearances of these three phases after Groesbeck's solution etching are shown in Figure 1. In sufficient quantity, $\sigma$ phase was usually present in stringer form along the rolling direction of the bar. Ferrite also usually existed in elongated shape on the longitudinal section of bars. Clearly, the tint etching made the two phases more distinguishable from each other. In addition, $\sigma$ stringers and ferrite were also different from each other in morphology. As shown in Figure 1, $\sigma$ phase usually exhibited a "lace" type pattern. On the other hand, ferrite stringers were more bulky.

Groesbeck's solution was effective in revealing $\sigma$ phase and differentiating it from other phases in AISI 316 stainless steel. However, maintaining appropriate temperature and the length of etching 
time made this method less convenient, especially when the characterization was conducted in a large volume of specimens.

In duplex stainless steels, due to the high $\mathrm{Cr}$ and Mo contents, the potential presence of $\sigma$ phase is a closely monitored feature. An electrolytic etching method described in ASTM A923, method A [2] proved very convenient for revealing $\sigma$ phase in AISI 316 stainless steel. This method is especially easy to use because it is a voltage controlled etching method, instead of a current proportional one. Therefore, no surface area calculation of the specimen is needed. In $40 \% \mathrm{NaOH}$ solution with around $2 \mathrm{~V}$ voltage at room temperature, 10 seconds of electrolytic etching gave a similar result as the tint etching using Groesbeck's solution, as shown in Figure 2. The $\sigma$ phase exhibited the similar orange-brown tint described earlier. Ferrite appeared either light brown or bluish gray.

In summary, two effective etching methods, tint etching and electrolytic etching, successfully revealed $\sigma$ phase and differentiated it from other phases in AISI 316 stainless steel. The method based on ASTM A923 method A was faster and easier to control than tint etching with Groesbeck's solution, while presenting similar results.

\section{References}

[1] George Vander Voort, Metallography Principles and Practice, McGraw-Hill, Inc., 1984 [2] ASTM A923-01, Standard Test Methods for Detecting Intermetallic Phase in Wrought Duplex Austenitic/Ferritic Stainless steels

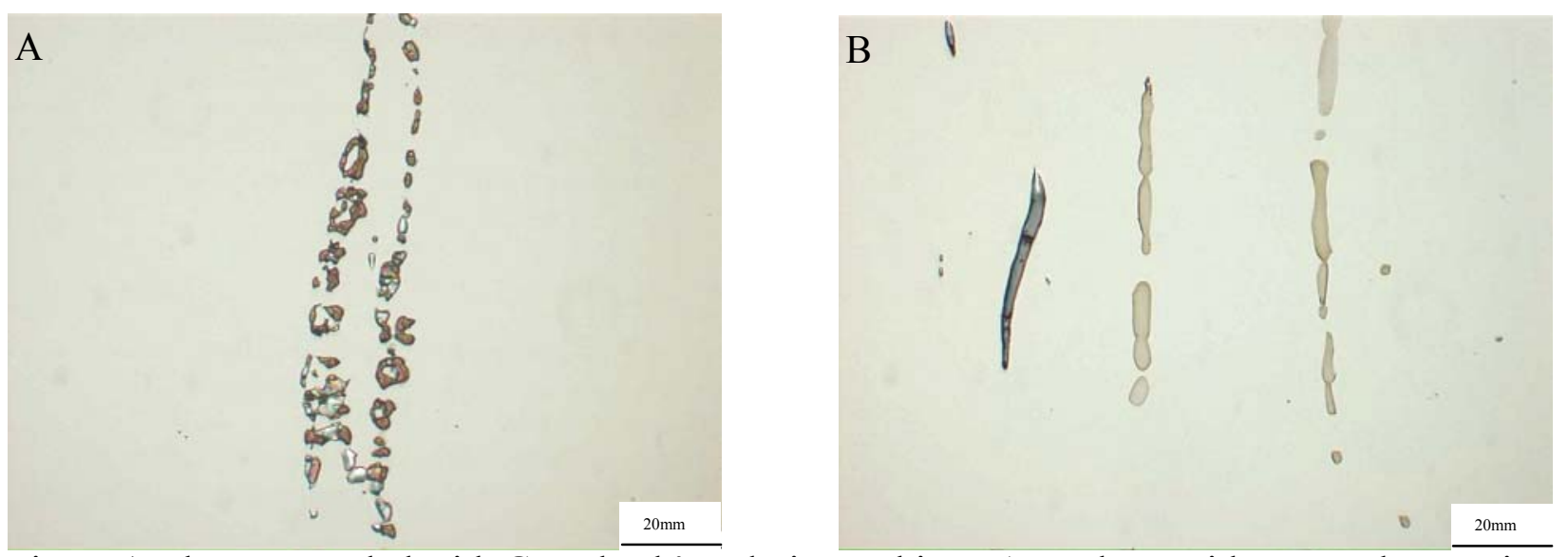

Figure 1 Phases revealed with Groesbeck's solution etching. A. $\sigma$ phase with orange-brown tint. B. MnS of dark gray and ferrite of light brown.

A

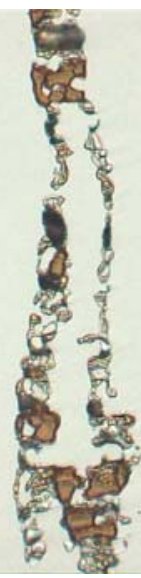

$\mathrm{B}$

$20 \mathrm{~mm}$

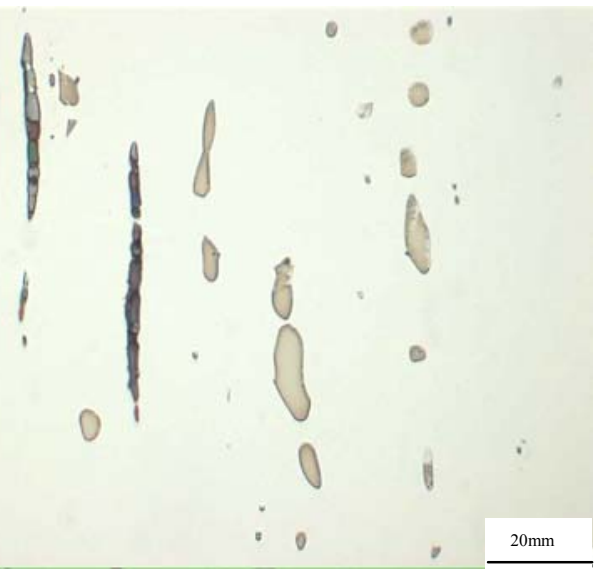

Figure 2 Phases revealed using method $\overline{\mathrm{A} \text { of }}$ ASTM A923. A. $\sigma$ phase. B. MnS and ferrite. 